\title{
London buses converted to dental surgeries to treat homeless people
}

\author{
A homelessness support initiative called \\ Driving for Change has refurbished two \\ London buses to offer healthcare and \\ dental services to homeless people. \\ The Change Please Foundation had \\ previously repurposed and fitted out buses \\ to provide essential services and facilities \\ to the homeless such as doctors, vets, \\ banking, showers, hair dressing, financial \\ literacy training and therapy assessments.
}

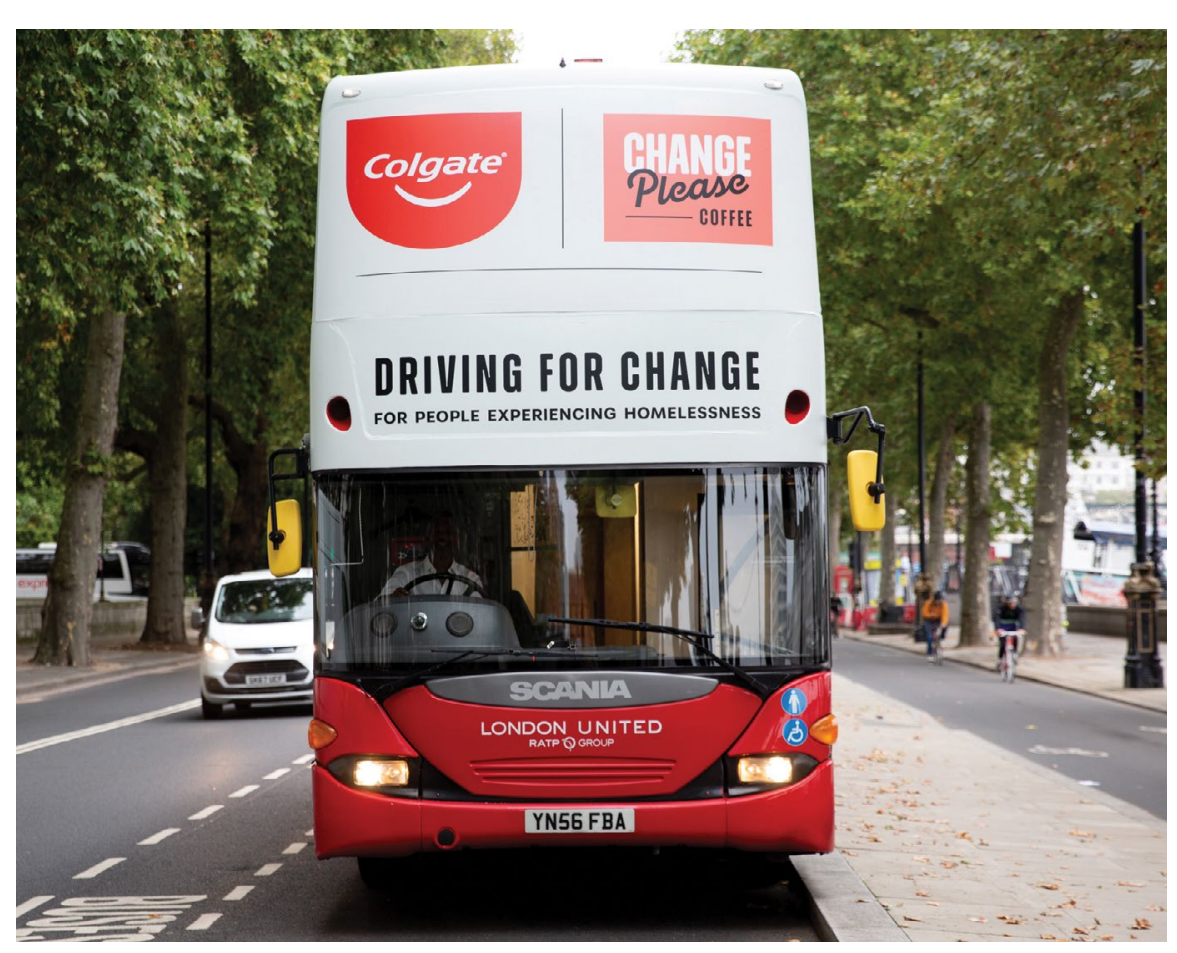

They had a vision to add dental services, housed inside a bus, that could be driven to homeless people as part of their Driving for Change initiative.

Change Please approached Eclipse Dental Engineering Ltd, a Greater London-based company providing solutions for those wanting to create, improve or maintain their surgeries, with their brief. Change Please asked for Eclipse Dental's assistance in

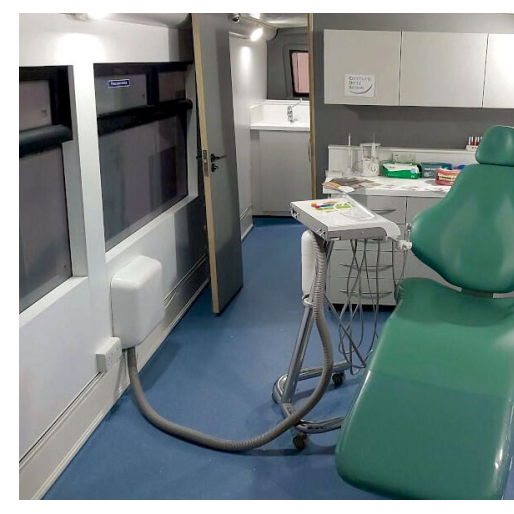

refurbishing the buses so that they could be launched ahead of World Homeless Day with London Mayor Sadiq Khan on 10 October 2021.

Meetings went ahead to find workable solutions to installing a dental surgery and decontamination room on the bus, including finding the best choices for air compressor, suction pump and autoclave with the lowest possible electrical supply requirement.

Sadiq Khan commented: 'As a son of a bus driver I'm so proud to see our buses used in this way'.

According to Change Please, the numbers of rough sleepers in the UK have risen exponentially over the past 18 months, with an estimated 130,000 households made homeless due to the COVID-19 pandemic. Driving for Change will give people experiencing homelessness pathways to potentially life-saving key services. To find out more, visit www.changeplease.org/pages/ driving-for-change.

\section{NASDAL DCby1 Practice of the Year Award launches}

Chairman of the National Association of Specialist Dental Accountants and Lawyers (NASDAL) Nick Ledingham has announced the launch of the 2022 NASDAL Dental Check by One Practice of the Year award. The award seeks to recognise a practice that has successfully introduced the British Society of Paediatric Dentistry (BSPD) Dental Check by One into their practice. The aim of the campaign is to increase the number of children who access dental care aged $0-2$ years.

Established in 2018, the award seeks to highlight excellence in the provision of oral care and prevention in children and showcase the opportunity to achieve a real business improvement. Particular credit is given to applications from dental practices with evidence supporting their contribution to the overall health of their community. The award will be presented by the Chief Dental Officer for England, Sara Hurley, at the BDIA Dental Showcase in Docklands ExCeL on 25 March 2022.

Nick Ledingham, Chairman of NASDAL, said: 'We look forward to hearing how the entrants have reached out to their communities and engaged with families. Following the COVID pandemic, we feel sure that there will be even more inspiring stories. We know that doing the right thing makes good business sense and this award recognises those practices whose efforts and imagination have inspired more parents to bring their baby or toddler in for a dental check by one'.

Practices who are interested in entering the 2022 NASDAL DCbyl award should visit https://www.nasdal.org.uk/award, where they will find all the relevant details and can register. All entries must be submitted before 5 pm, Monday 31 January 2022. The winning practice will receive $£ 1,000$, a trophy and the right to use the NASDAL Dental Check by One Practice of the Year 2022 title. 